\title{
Effects of Memantine on Neuronal Structure and Conditioned Fear in the Tg2576 Mouse Model of Alzheimer's Disease
}

\author{
Hongxin Dong', Carla M Yuede', Carolyn Coughlan', Brian Lewis' and John G Csernansky*,',2 \\ 'Departments of Psychiatry, Washington University School of Medicine, St Louis, MO, USA; ${ }^{2}$ Anatomy and Neurobiology, Washington University \\ School of Medicine, St Louis, MO, USA
}

\begin{abstract}
Memantine, an uncompetitive NMDA receptor antagonist used for the treatment of Alzheimer's disease (AD), has been hypothesized to have neuroprotective properties. However, the similarity of its mechanism of action to other NMDA receptor antagonists has led to concerns that it may also have neurotoxic effects. To assess both the neuroprotective and neurotoxic potential of memantine in a mouse model of AD (Tg2576 mice), we used quantitative light and electron microscopy to investigate the effects of long-term (6 months) administration of memantine $(5,10$ and $20 \mathrm{mg} / \mathrm{kg}$ ) on plaque deposition and neuronal morphology in the hippocampus and overlying cortex. A fear-conditioning paradigm was used to evaluate the behavioral consequences of any observed changes in structure. Administration of the two higher doses of memantine $(10$ and $20 \mathrm{mg} / \mathrm{kg}$ ) was associated with a significant decrease in $\beta$-amyloid $(A \beta)$ plaque deposition, increases in synaptic density and the appearance of degenerating axons; the latter two effects were independent of genotype. Administration of the lowest dose of memantine $(5 \mathrm{mg} / \mathrm{kg})$ was associated with a significant decrease in $A \beta$ plaque deposition and a significant increase in synaptic density, but not a significant increase in degenerating axons. However, memantine did not significantly improve behavioral deficits associated with genotype in a fear-conditioning paradigm at any dose. These results suggest that chronic memantine administration may have both neuroprotective and neurotoxic effects in a mouse model of AD. Neuropsychopharmacology (2008) 33, 3226-3236; doi:I0.1038/npp.2008.53; published online 16 April 2008
\end{abstract}

Keywords: memantine; synapse density; amyloid plaque; conditioned fear; Tg2576 mice; Alzheimer's disease

\section{INTRODUCTION}

Memantine, an uncompetitive antagonist at NMDA receptors (Kornhuber et al, 1989; Chen et al, 1992), is now widely prescribed for the treatment of moderate-to-severe Alzheimer's disease (AD). Memantine is rapidly displaced from the NMDA receptor, which may avoid prolonged receptor blockade and the detrimental effects on learning and memory associated with prolonged blockade of the NMDA receptor (Lipton, 2006). Further, memantine acts as an antagonist at nicotinic acetylcholine receptors and at 5-HT receptors (Buisson and Bertrand, 1998; Aracava et al, 2005). The rationale for using memantine in $\mathrm{AD}$ patients is based on the hypothesis that blockade of NMDA receptormediated excitotoxicity can help preserve neuronal structure and function (Lipton, 2006, 2007; Wenk et al, 2006). The ability of memantine to protect neurons against NMDA- or glutamate-induced excitotoxicity has been shown in vitro (Erdö and Schäfer, 1991; Chen et al, 1992;

*Correspondence: Dr JG Csernansky, Department of Psychiatry, Washington University School of Medicine, 660 South Euclid Avenue, Campus Box 8134, St Louis, MO 631 I0, USA, Tel: + I 314747 2160, Fax: + | 314747 2182, E-mail: jgc@conte.wustl.edu

Received 5 October 2007; revised 26 February 2008; accepted 6 March 2008
Weller et al, 1993), and in animal models of neurodegenerative disease (Wenk et al, 1995, 1997, 2006; MiguelHidalgo et al, 2002). Therefore, it has been proposed that memantine can improve cognition in $\mathrm{AD}$ and perhaps even slow disease progression by blocking NMDA receptormediated excitotoxicity (Ditzler, 1991; Frankiewicz et al, 2000; Reisberg et al, 2003; Lipton, 2006). However, concerns have also been raised about the potential for memantine to damage neurons given that other NMDA receptor antagonists, such as phencyclidine and MK-801, have been shown to trigger neuronal degeneration in rodents ( $\mathrm{Li}$ et al, 2002; Creeley et al, 2006). At present, there are no published postmortem data that can be used to assess the potential for memantine to either slow or induce neuronal degeneration in patients with $\mathrm{AD}$. Thus, whether long-term memantine treatment can reverse or prevent damage to areas of the brain resulting from $\mathrm{AD}$ pathology remains unclear.

In the current study, we used quantitative light and electron microscopic studies of the hippocampus and overlying cortex, and contextual memory as assessed in a conditioned fear paradigm, to assess the effects of chronic administration of memantine on neuronal structure and function in the Tg2576 mouse model of AD. We focused our structural assessments on the hippocampal formation because these structures play a major role in learning and memory (Knowles, 1992; Bannerman et al, 2001) and is also 
a site for $\mathrm{A} \beta$ deposition in $\mathrm{AD}$ patients (Probst et al, 1983; West et al, 2004) and in several transgenic mouse models of $\mathrm{AD}$ ( $\mathrm{Su}$ and Ni, 1998; Reilly et al, 2003). Synapse loss induced by $\mathrm{A} \beta$ remains a likely basis for the behavioral deficits observed in Tg2576 mice (Stern et al, 2004). Previously, we demonstrated spatial and temporal relationships between synapse loss and $\mathrm{A} \beta$ deposition in the dentate gyrus of Tg2576 mice at 6-9 months of age (Dong et al, 2007). In this study, the effects of memantine on $\mathrm{A} \beta$ deposition and neuronal structure in the hippocampus and overlying cortex and contextual memory were assessed in transgenic Tg2576 mice at 9-10 months of age, following 6 months of memantine or vehicle administration. In addition, we evaluated plaque deposition in the cortex overlying the hippocampus and looked for evidence of memantine-induced neuronal vacuolization in the posterior cingulate and retrosplenial cortices under light microscopy.

\section{MATERIALS AND METHODS}

\section{Animals}

The Tg2576 mouse strain, created by Hsiao et al (1996), was used for these experiments. Tg2576 mice were derived from C57B6/SJL $\times$ C57B6 crosses, and contained the double mutation Lys670-Asn, Met671-Leu (K670N, M 671L). This mutation is driven by a hamster prion protein gene promoter in $\mathrm{C} 57 \mathrm{~B} 6 \mathrm{j} \times \mathrm{SJL}$. Brain levels of APP are more than four times higher, and $\mathrm{A} \beta$ levels are 5-14 times higher, in transgenic mice than in control mice. The presence of the human APP gene was demonstrated by post-weaning tail biopsy and DNA genotyping using primers as previously described (Hsiao et al, 1996). The breeding and maintenance of the $\operatorname{Tg} 2576$ mouse colony were conducted in consultation with the veterinary staff in the Department of Comparative Medicine at Washington University School of Medicine. All animal procedures were done in accordance with the National Institutes of Health and Institutional Guidelines.

Transgenic mice that express the human APP gene $(\mathrm{Tg}+)$ and their non-transgenic ( $\mathrm{Tg}-$ ) littermates were randomly assigned to various groups for memantine administration. A total of 89 animals of both genders $(\mathrm{Tg}+=42$; $\mathrm{Tg}-=47)$ were used for this study. Eighty-four animals were used for behavioral tests $(5 \mathrm{mg} / \mathrm{kg}(\mathrm{Tg}+=12, \mathrm{Tg}-=10) ; 10 \mathrm{mg} / \mathrm{kg}$ $(\mathrm{Tg}+=17, \mathrm{Tg}-=10) ; 20 \mathrm{mg} / \mathrm{kg}(\mathrm{Tg}+=9 ; \mathrm{Tg}-=12)$ and vehicle $(\mathrm{Tg}+=8, \mathrm{Tg}-=6))$. After behavioral testing, 38 of these animals were used to assess neuronal density and ultra-structure changes $(5 \mathrm{mg} / \mathrm{kg} \quad(\mathrm{Tg}+=4, \mathrm{Tg}-=4)$; $10 \mathrm{mg} / \mathrm{kg}(\mathrm{Tg}+=4, \mathrm{Tg}-=4) ; 20 \mathrm{mg} / \mathrm{kg}(\mathrm{Tg}+=6, \mathrm{Tg}-=4)$ and vehicle $(\mathrm{Tg}+=6, \mathrm{Tg}-=6))$, and $22 \mathrm{Tg}+$ mice were used to measure amyloid plaques $(5 \mathrm{mg} / \mathrm{kg}(\mathrm{Tg}+=4)$, $10 \mathrm{mg} / \mathrm{kg} \quad(\mathrm{Tg}+=8), 20 \mathrm{mg} / \mathrm{kg}(\mathrm{Tg}+=5)$, and vehicle $(\mathrm{Tg}+=5))$.

\section{Drug Treatment}

Approximately equal groups of $\mathrm{Tg}+$ and $\mathrm{Tg}-$ mice received one of three daily doses of memantine or vehicle for 6 months beginning at 3 months of age. Three doses of memantine (equivalent to 5,10 , and $20 \mathrm{mg} / \mathrm{kg} /$ day) were dissolved in drinking water that was prepared fresh weekly.
To ensure the consistency of drug dosing and that the presence of memantine did not influence daily water consumption, we measured the amount of water consumed in individual mice weekly and calculated total and mean volume of drinking water with and without drug. The volume of consumption within individual mice was significantly different $(\mathrm{F}(250,9)=8.55, p<0.0001)$, but the mean amount of consumption between groups was not significantly different $(\mathrm{F}(38,1)=0.195, p=0.66)$.

\section{Conditioned Fear Testing}

The assessment of contextual and cued memory within a fear-conditioning paradigm was performed using methods previously described (Bardgett et al, 2003; Dong et al, 2005). Animals were trained and tested in two Plexiglas conditioning chambers $(26 \times 18 \times 18 \mathrm{~cm})$ (Med Associates Inc., Georgia, VT), with a metal grid floor, within a larger sound-attenuating chamber. On day 1, training took place in the first chamber which contained a cup containing mint extract placed beneath the grid floor. Freezing behavior, defined as no movement (ambulation, sniffing or stereotypy) other than respiration, was recorded every $10 \mathrm{~s}$ for $5 \mathrm{~min}$. After the first $2 \mathrm{~min}$, a $20 \mathrm{~s}, 80 \mathrm{~dB}$, a $2800 \mathrm{~Hz}$ tone was presented, and during the last $2 \mathrm{~s}$ of the tone, the animals received a $1.0 \mathrm{~mA}$ continuous footshock. This procedure was repeated two more times at 1 min intervals. On day 2 , animals were returned to the chamber and the amount of freezing behavior in response to context (ie memory for context) was recorded every $10 \mathrm{~s}$ for $8 \mathrm{~min}$. On day 3 , the animals were placed in a second chamber (scented with coconut with the grid floor covered with polyurethane). Freezing behavior was again recorded for $2 \mathrm{~min}$. Then, the $80 \mathrm{~dB}, 2800 \mathrm{~Hz}$ tone was represented continuously for $8 \mathrm{~min}$, and freezing behavior in response to the cue was recorded.

Sensitivity to the footshock was tested on the day following completion of the cued conditioning evaluation. The animals were returned to the first conditioning chamber for $2 \mathrm{~min}$ and exposed to a series of $2 \mathrm{~s}$ shocks, beginning with an intensity of $0.05 \mathrm{~mA}$. The shock intensity was increased by $0.05 \mathrm{~mA}$ every $20-30 \mathrm{~s}$ until a jumping response was evoked.

\section{Tissue Preparation}

For $\mathrm{A} \beta$ plaque evaluation, animals were deeply anesthetized and perfused transcardially with $1 \%$ heparinized $0.01 \mathrm{M}$ phosphate-buffered saline (PBS) for $2 \mathrm{~min}$ and then $4 \%$ paraformaldehyde for 25-30 min. Brains were removed and post-fixed overnight at $4{ }^{\circ} \mathrm{C}$ using the same fixative with $30 \%$ sucrose. The brains were cut into $35 \mu \mathrm{m}$ thick serial sections in the coronal plane using a cryostat (Leica CM $1850 \mathrm{UV}$, Nussloch, Germany). Of the six series of sections (15-20 sections each), we used one series for Thioflavine $S$ staining to assess compact (fibrillar) $\mathrm{A} \beta$ plaques and plaque burden. Floating sections in a $1 \%$ Thioflavine $S$ aqueous solution for $5 \mathrm{~min}$ then differentiated in $70 \%$ alcohol for 3-5 min (Guntern et al, 1992).

For studies of neuronal density and ultra-structure, animals were deeply anesthetized and perfused transcardially with $0.01 \mathrm{M}$ PBS-containing heparin sodium for $2 \mathrm{~min}$, followed by a $30 \mathrm{~min}$ perfusion with $2 \%$ paraformal- 
dehyde, $2 \%$ glutaraldehyde and $4 \%$ sucrose in $0.1 \mathrm{M}$ PBS. Sections $250 \mu \mathrm{m}$ thick were cut in the coronal plane using a vibratome. Fifteen sections encompassing the whole hippocampus were selected from each brain and were rinsed in cold $0.1 \mathrm{M}$ PBS, treated with $2 \% \mathrm{OsO}_{4}$ in $0.1 \mathrm{M}$ PBS for $90 \mathrm{~min}$ at $4^{\circ} \mathrm{C}$ and rinsed again in $0.1 \mathrm{M}$ PBS at room temperature. The sections were then dehydrated in a graded series of ethanol solutions, followed by propylene oxide, and left overnight in a 1:1 mixture of propylene oxidePolybed 812 (Electron Microscopy Sciences, Hatfield, PA). Finally, the sections were flat embedded in Polybed 812 in an oven at $60^{\circ} \mathrm{C}$ for $48-72 \mathrm{~h}$. From the 15 embedded sections, three were selected for semi- and ultra-thin sectioning. Representative sections included the dorsal, medial and ventral hippocampus and underlying cortex.

Selected embedded sections ( $250 \mu \mathrm{m}$ thick) were trimmed and sectioned again using a Reichert Ultracut E Ultramicrotome (Austria). Semi-thin $(1 \mu \mathrm{m})$ sections that included hippocampus and underlying cortex were cut and stained with toluidine blue for studying overall histopathological changes in the posterior cingulate and retrasplenial cortices and the hippocampus. The semi-thin sections were also served as reference sections for ultra-thin cutting. The sections were then continued to be trimmed and ultra-cut the thin $(75-90 \mathrm{~nm})$ sections containing the outer molecular layer of the dentate gyrus (dorsal blade), which were mounted on 400-mesh grids (every mesh grid is $62 \times 62 \mu \mathrm{m}^{2}$, Electron Microscopy Sciences, Hatfield, PA). The sections were stained using 3\% uranyl acetate for $20 \mathrm{~min}$ followed by lead citrate for $5 \mathrm{~min}$ and then were examined using a JEOL 100 CX electron microscope (Japan).

\section{Quantitative Evaluation of $\beta$-Amyloid Plaque Deposition}

$\mathrm{A} \beta$ plaques were measured in the hippocampus and overlying cortex using non-biased stereological methods, as described previously (Dong et al, 2004, 2007). The stereological system program (Olympus, Albertslund, Denmark) was used to measure $\mathrm{A} \beta$ plaque number and burden (total $\mathrm{A} \beta$ plaque area/brain area in coronal section). The numbers calculated from one series of sections were multiplied by six to obtain an estimate of total $\mathrm{A} \beta$ plaque number and burden per brain.

\section{Quantitative Evaluation of Neuronal Morphology}

Two to three semi-sections from each brain were selected to look for evidence of memantine-induced changes in neuronal morphology, and in particular vacuolization, in the hippocampus and in the posterior cingulate and retrosplenial cortices. The selected coronal sections were cut at the level of the decussation of the corpus callosum (approximately -5.30 to $-5.60 \mathrm{~mm}$ caudal to bregma) to ensure sampling each brain at the same rostrocaudal level. Also, the brain regions selected using this sampling scheme have been reported to be particularly vulnerable to vacuolization induced by the administration of NMDA antagonists (Fix et al, 1993, 1994; Creeley et al, 2008). A total of 10 neurons in each section of the posterior cingulate and retrosplenial cortices and the hippocampus were detected (under $\times 100$ objective lens) and evaluated for the presence and severity of interacytoplasmic vacuoles and other features of neuronal damage. Neuronal number in the retrosplenial cortex was also counted using stereological methods. Only neurons with a visible nucleolus were counted (under $\times 40$ objective lens). The unbiased counting frame was $185000 \mu \mathrm{m} \times 147000 \mu \mathrm{m}=2.72 \times 10^{10} \mu \mathrm{m}^{2}$, the dissector height was $1 \mu \mathrm{m}$, and the dissector volume was $2.72 \times 10^{10} \mu \mathrm{m}^{3}$. The latter value was used to calculate the density of neurons as the quotient of the mean number of neuron counted per dissector and the mean volume of dissectors.

\section{Quantitative Evaluation of Synapse Density and Axon Morphology}

At low magnification under the electron microscope, the boundaries of the outer molecular layer of the dentate gyrus were identified according to their characteristic cellular structures (Figure 1a). Then, 8-15 photographs from each electron microscope section were taken systematically at $\times 800$ magnification using alternate grid squares (Figure 1b). Three sections from each animal, including the dorsal, medial and ventral dentate gyrus, were assessed. A total of 1140 photographs were taken for analysis. Synapses were identified under electron micrographs that were enlarged photographically to a final magnification of $\times 29000$. A magnification standard (grating replica) was used for each series of electron micrographs. Synapses in the molecular layer of dentate gyrus were identified on photographs by the presence of synaptic vesicles and postsynaptic densities (Figure 1c). Asymmetrical (ie excitatory glutamatergic synapses) and symmetrical synapses (ie inhibitory GABAergic synapses) (Watson, 1988; Kennedy, 2000; Lund et al, 2001) were counted separately. Degenerating axons were identified on photographs by the presence of vesicular and lamellar debris within the atrophic axon. A stereological dissector technique was used to measure the density of synapses and degenerating axons (West and Gundersen, 1990; Geinisman et al, 2000; Dong et al, 2007). Each dissector consisted of micrographs of two adjacent ultrathin sections, a reference section and a look-up section immediately above it. Only synapses or axons that occurred in the reference, but not in the look-up section, were counted. The area of the unbiased counting frame was $247 \mu \mathrm{m}^{2}$, the dissector height was $0.085 \mu \mathrm{m}$, and the dissector volume is $20.99 \mu \mathrm{m}^{3}$. The latter value was used to calculate the density of synapses or degenerating axons (synapses or axons per unit volume) as the quotient of the mean number of synapses or axons counted per dissector and the mean volume of dissectors.

\section{Statistical Analysis}

Anatomic variables were compared across groups using a two-way analysis of variance (ANOVA). Freezing behavior was analyzed using repeated measures ANOVA with minute as the repeated measure, and shock sensitivity was analyzed with factorial ANOVA. Statistical significance was accepted for $p$-values less than 0.05 . When significant genotype effects (ie $(\mathrm{Tg}+)$ mice $v s(\mathrm{Tg}-)$ controls), drug effects, or genotype $\times$ drug interactions were found, post-hoc analyses 

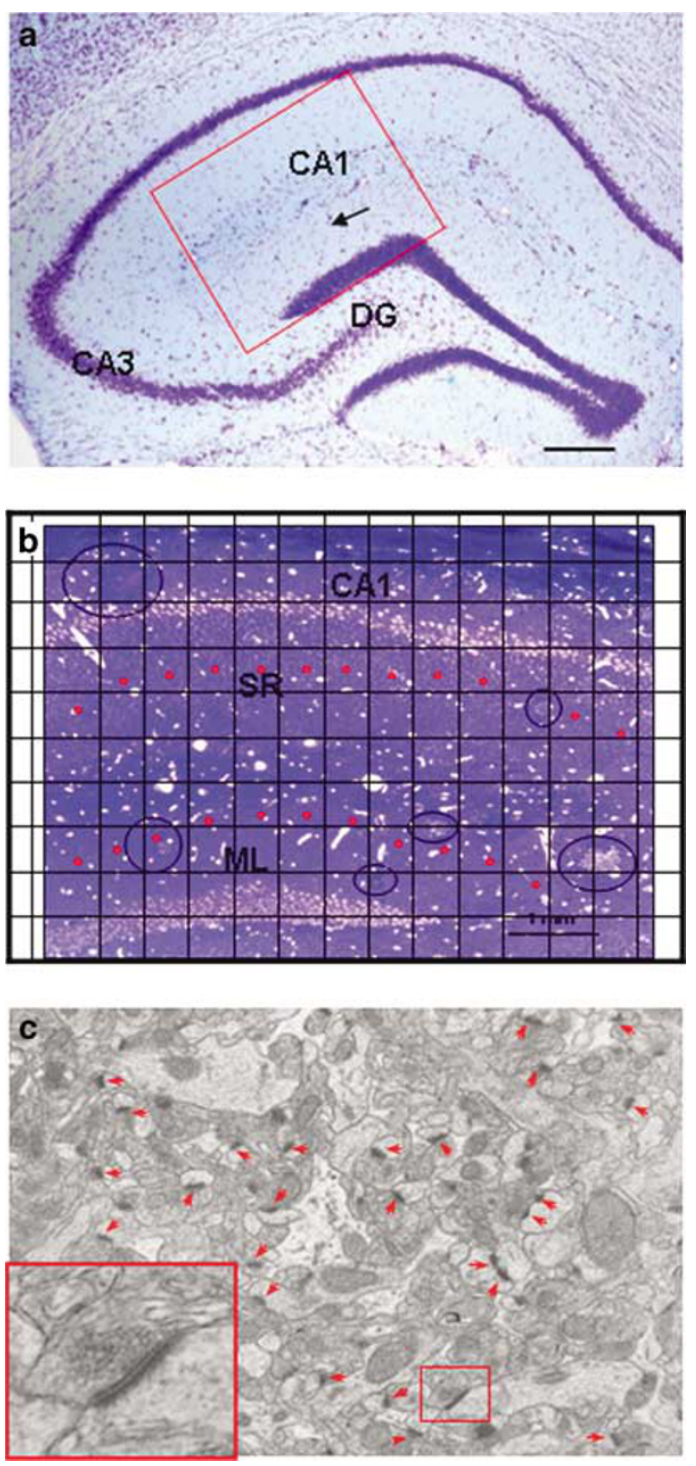

Figure I (Panel a) A section through the hippocampus. The rectangle indicates the ultrasection that was trimmed and cut, which included the stratum radiatum of CAI and molecular layer of dentate gyrus. (Panel b) Semi-section through the hippocampus adjacent to the ultrasection. The section and grid schematically indicates the samplings made under electron microscopy. One photograph from each grid mesh (Red dots indicated) that covered the SR and ML of dentate gyrus was taken systematically. For this study, only ML of dentate gyrus was counted for analysis. (Panel c) EM photographs used to examine the neuronal structure and synapses. The red dots indicate the synapses that were counted. Synapses were identified by the presence of synaptic vesicles and postsynaptic densities (see high magnification inset)

were performed using a Fisher's Protected Least Squares Design tests.

\section{RESULTS}

\section{Plaque Density in the Hippocampus and Overlying Cortex}

In $\mathrm{Tg}+$ mice at 9 months of age, small $\mathrm{A} \beta$ plaques $(<50 \mu \mathrm{m}$ in diameter) were observed in the hippocampus and overlying cortex, in keeping with previous findings
(Figure 2). No $\mathrm{A} \beta$ plaques were observed in $\mathrm{Tg}-$ animals, and therefore $\mathrm{Tg}-$ mice were not included in further analyses for this variable. Memantine administration was associated with decreases in amyloid deposition in $\mathrm{Tg}+$ mice (Figure 2b-d). A significant effect of memantine administration was found on total plaque number $(\mathrm{F}(3,19)=8.13, p=0.001)$ (Figure $3 \mathrm{a})$ and plaque burden $(\mathrm{F}(3,16)=5.58, p=0.008)$ ) (Figure 3b). Post hoc tests showed that all three doses of memantine significantly reduced plaque number and burden as compared to vehicle $(p<0.02)$. Further, the $5 \mathrm{mg} / \mathrm{kg}$ treatment group showed fewer plaques than the $10 \mathrm{mg} / \mathrm{kg}$-treated group $(p<0.03)$, while the difference between 10 and $20 \mathrm{mg} / \mathrm{kg}$-treated groups was not significant (Figure $3 a$ and $b$ ).

\section{Neuronal Morphology in the Posterior Cingulate, Retrosplenial Cortices and the Hippocampus}

Following long-term administration of memantine at all doses to both $\mathrm{Tg}+$ and $\mathrm{Tg}-$ mice, the hippocampus and selected regions of the cortex had a generally normal appearance under light microscopy. In particular, we did not observe aberrant vacuolization in the cytoplasm of pyramidal neurons in the hippocampus, or in the posterior cingulate, retrosplenial cortices (Figure 4). However, a number of cells appeared to be darkly stained in these areas. Some of the dark cells showed features of neurodegeneration (Figure 4a, arrow indicated) but whether these cells were undergoing cell death could not be confirmed. The density of dark cells in the posterior cingulate and retrosplenial cortices was not significantly affected by either genotype drug administration (data not shown). However, there was a trend towards a drug effect $(\mathrm{F}(1,24)=2.91$; $p=0.055)$, but not a genotype effect $(\mathrm{F}(1,24)=0.11$, $p=0.74)$, nor a drug $\times$ genotype interaction $(\mathrm{F}(1,24)=1,93$; $p=0.15$ ), on neuronal density in the retrosplenial cortex.

\section{Synapse Density}

Increased synapse density was observed after memantine administration in the molecular layer of the dentate gyrus in both $\mathrm{Tg}+$ and $\mathrm{Tg}-$ mice (Figure 5). There was a significant effect of memantine administration on synapse density $(\mathrm{F}(3,30)=4.86, p=0.007)$, but no overall effect of genotype $(\mathrm{F}(3,30)=0.38, p=0.54)$, nor a drug $\times$ genotype interaction (Figure 6). Post hoc tests indicated that all three doses of memantine significantly increased synapse density as compared to vehicle $(p<0.02)$, with no significant differences between doses. Further, a significant decrease in synapse density was found post hoc in vehicle-treated transgenic animals $(\mathrm{Tg}+)$ as compared to vehicle-treated non-transgenic animals $(\mathrm{Tg}-)(\mathrm{F}(1,10)=9.04, p=0.013)$ (Figure 6a).

The changes in synapse density related to both genotype and memantine treatment were largely confined to asymmetric synapses. In the molecular layer of the dentate gyrus, $92.5 \%$ of total synapses in $\mathrm{Tg}+$ mice and $90.3 \%$ of total synapses in $\mathrm{Tg}-$ mice were asymmetrical (ie glutamatergic synapses), and $4.8 \%$ of total synapses in $\mathrm{Tg}+$ mice and $5.6 \%$ of total synapses in $\mathrm{Tg}-$ mice were symmetrical (ie GABAergic synapses). The remaining (2.7-4.1\%) synapses were labeled as unidentified because it was 

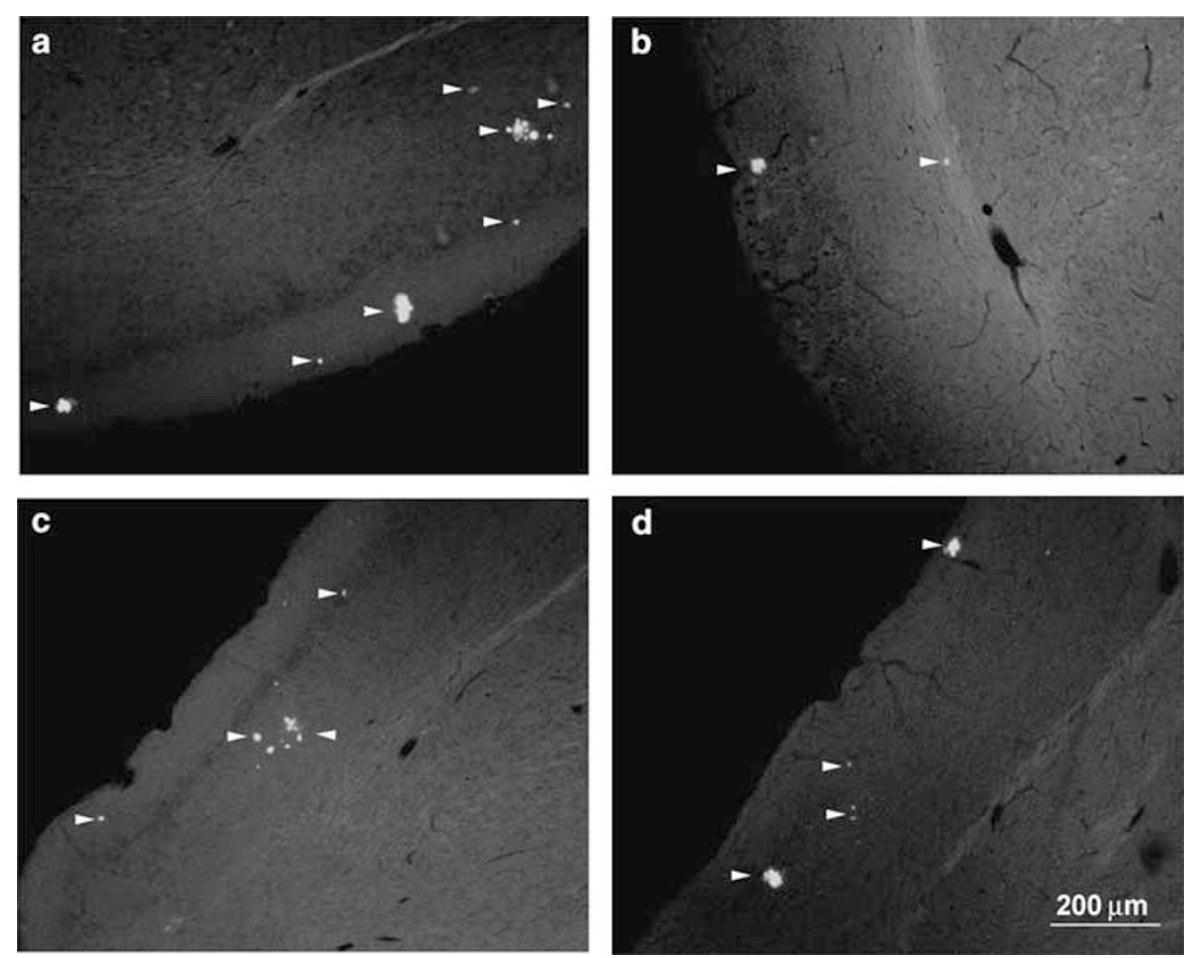

Figure $2 \beta$-Amyloid plaque stained by Thioflavine $\mathrm{S}$ in the brain of 9-10 months old $\mathrm{Tg}+$ mice treated with 5,10 and $20 \mathrm{mg} / \mathrm{kg}$ of memantine and vehicle. Memantine administration for 6 months decreased $\beta$-amyloid plaque deposition in the entorhinal cortex $(\mathrm{Tg}+\mathrm{mice}$ with $5 \mathrm{mg} / \mathrm{kg}$ (panel b), $10 \mathrm{mg} / \mathrm{kg}$ (panel c), and $20 \mathrm{mg} / \mathrm{kg}$ (panel d) as compared to vehicle $\mathrm{Tg}+$ mouse (panel a). Arrow heads indicate the plaques. Bar in panel $\mathrm{d}$ also applies to a, b and c.

difficult to classify them as either asymmetrical or symmetrical synapses. In the vehicle-treated group, there was a significant genotype effect $(\mathrm{F}(1,10)=10.96 ; p=0.008)$ on density of asymmetrical synapses, but not on the density of symmetrical synapses $(\mathrm{F}(1,10)=1.87 ; p=0.202)$. In the memantine-treated groups, there was also a significant drug effect on the density of asymmetrical synapses $(\mathrm{F}(3,30)=4.40$; $p=0.01)$, but not the density of symmetrical synapses $(\mathrm{F}(3,30)=2.225 ; p=0.106)$.

\section{Degenerating Axons}

In animals treated with memantine, but not vehicle, we noted the presence of a marked increase in degenerating axon terminals or degenerated debris. Degenerating axons were identified by a variety of pathologic features including myelin degradation products, disorganization of the axoplasm, and disintegration of the internal part of the myelin, along with various vesicular and lamellar debris within the atrophic axon (Figure 5, arrows indicated). There was a significant effect of memantine administration on the density of degenerating axons $(\mathrm{F}(3,30)=10.7, p<0.001)$ (Figure 6b), but no effect of genotype $(\mathrm{F}(3,30)=0.384, p=$ $0.54)$, nor a genotype $\times$ memantine interaction $(F(3,30)=1.62$, $p=0.206$ ). Post hoc tests showed that treatment with the two higher doses of memantine $(10$ and $20 \mathrm{mg} / \mathrm{kg})$ were associated with significant increases in the density of degenerating axons as compared to vehicle $(p$ 's $<0.001)$, and the lowest dose of memantine treatment $(5 \mathrm{mg} / \mathrm{kg})$ $(p$ 's $<0.02)$ in both $\mathrm{Tg}+$ and $\mathrm{Tg}-$ mice.

\section{Conditioned Fear}

There was no significant effect of genotype $(\mathrm{F}(1,76)=1.01$, $p=0.32)$, memantine administration $(\mathrm{F}(3,76)=2.43, p=0.07)$ nor a genotype $\times$ memantine interaction $(F(3,76)=0.48$, $p=0.69$ ) on baseline freezing behavior, which suggested no differences between groups in activity level in response to the test chamber. There was a significant genotype $\times$ memantine $\times$ minute interaction $(\mathrm{F}(3,76)=2.85$, $p=0.04)$, and post hoc tests indicated that the $\mathrm{Tg}-5 \mathrm{mg} /$ $\mathrm{kg}$ memantine group froze significantly more than the $\mathrm{Tg}-10 \mathrm{mg} / \mathrm{kg}$ memantine and the $\mathrm{Tg}+20 \mathrm{mg} / \mathrm{kg}$ memantine groups during the second $\min (p$ 's $<0.05)$. Assessment of freezing behavior during the tone-shock presentation on day 1 revealed a significant effect of genotype $(\mathrm{F}(1,76)=26.33, p=0.00002)$, but no significant effect of memantine administration $(\mathrm{F}(3,76)=0.89, p=0.45)$, nor a genotype $\times$ memantine interaction $(F(3,76)=0.85$, $p=0.47)$. Post hoc tests indicate that the $\mathrm{Tg}-$ animals froze more in response to the tone-shock pairings than the $\mathrm{Tg}+$ animals $(p<0.01)$. Assessment of contextual memory on day 2 indicated a significant effect of genotype $(\mathrm{F}(1,76)=14.99, p=0.0002)$ but no effect of memantine $(\mathrm{F}(3,76)=0.02, \quad p=0.99)$, nor a genotype $\times$ memantine interaction $(\mathrm{F}(3,76)=0.33, p=0.80)$. Evaluation of freezing behavior in response to the altered context on day 3 revealed a significant effect of genotype $(F(1,76)=8.32$, $p=0.005)$, but no effect of memantine administration $(\mathrm{F}(3,76)=0.71, \quad p=0.55)$, nor a genotype $\times$ memantine interaction $(\mathrm{F}(3,76)=0.99, \quad p=0.40)$. Post hoc tests indicated that the $\mathrm{Tg}-$ mice froze significantly more than 

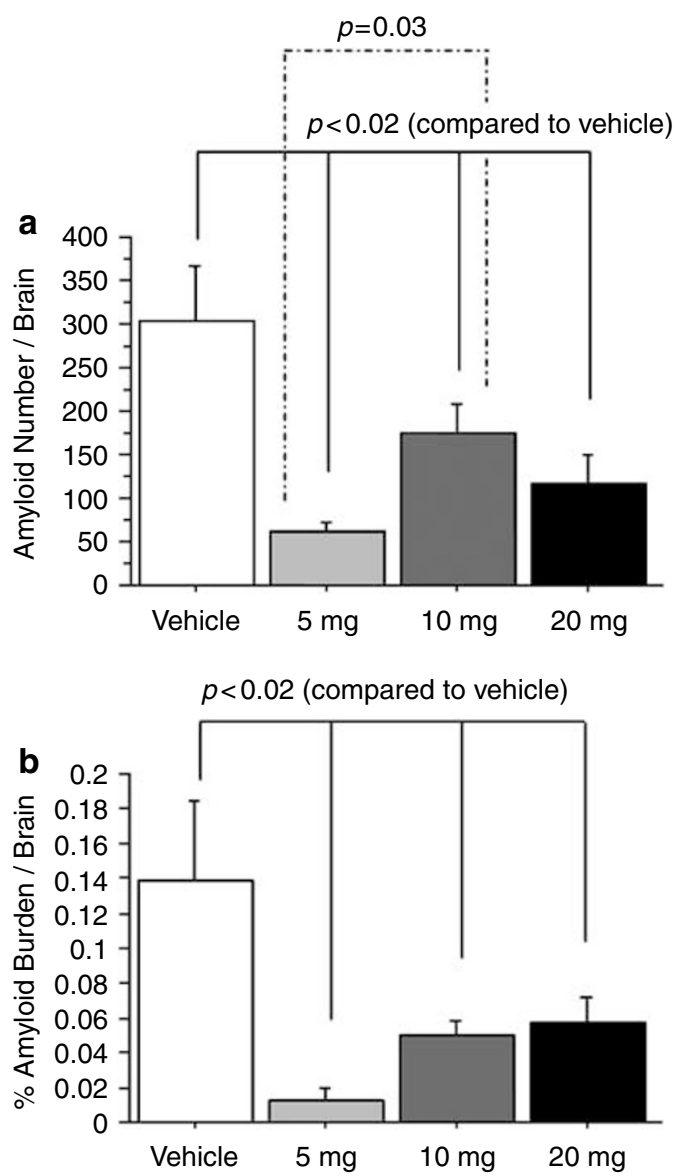

Figure $3 \beta$-Amyloid plaque number and burden in the brain of $\mathrm{Tg}+$ mice treated with 5,10 and $20 \mathrm{mg} / \mathrm{kg}$ of memantine. A significant drug effect was found on the total number of amyloid plaques in the brain (panel a) and the percentage of brain occupied by $\beta$-amyloid plaque (panel b).

$\mathrm{Tg}+$ mice $(p=0.01)$. Analysis of freezing behavior during presentation of the tone on day 3 indicated a significant effect of genotype $(\mathrm{F}(1,76)=12.82, p=0.0006)$, with post hoc tests showing that $\mathrm{Tg}+$ mice froze less than $\mathrm{Tg}-$ mice $(p=0.001)$. The effect of memantine administration $(\mathrm{F}(3,76)=1.31, p=0.28)$ was not significant, but there was a significant genotype $\times$ memantine interaction $(F(3,76)=2.76$, $p=0.048)$. Post hoc tests showed that the $\mathrm{Tg}+10 \mathrm{mg} / \mathrm{kg}$ memantine group froze significantly less than both the $\mathrm{Tg}-5$ and $10 \mathrm{mg} / \mathrm{kg}$ memantine groups $(p$ 's $<0.02)$ (Figure 7).

The observed power for the results of contextual fear conditioning was high for the genotype effect (0.99), but low (0.06) for the drug effect (calculated by SPSS). Although the sample sizes for our study were relative to those used in similar designs (Van Dam and De Deyn, 2006), it is possible that due to the variability in our sample sizes at each dose, our group numbers were too low to detect statistical significance.

Factorial ANOVA across groups revealed no significant differences in shock sensitivity due to genotype $(\mathrm{F}(1,76)=0.12, \quad p=0.73), \quad$ memantine administration
$(\mathrm{F}(3,76)=0.27, \quad p=0.85)$, nor a genotype $\times$ memantine interaction $(\mathrm{F}(3,76)=1.37, p=0.26)$.

\section{DISCUSSION}

In this study, we evaluated the effects of chronic memantine administration on amyloid plaque deposition and neuronal morphology using quantitative light and electron microscopy in Tg2576 mice, a commonly used animal model of AD. In addition, we sought to evaluate the behavioral consequences of any observed changes in structure by assessing contextual memory using a fear-conditioning paradigm. We found that chronic memantine administration decreased $\mathrm{A} \beta$ plaque burden in the brain, increased synapse density and increased degenerating axon density in the molecular layer of the dentate gyrus. While we didn't observe neuronal vacuolization following memantine administration, the appearance of degenerating axons after memantine administration was dose-dependent and consistent with some of the neurotoxic changes previously observed following administration of NMDA antagonists. However, despite these changes in amyloid deposition and neuronal structure, we did not find an effect of memantine on hippocampal-dependent contextual memory in $\mathrm{Tg}+$ mice.

Our results are consistent with previous studies which found decreases in cortical APP levels in Tg2576 mice after 10 days of memantine treatment (Unger et al, 2006). However, the mechanism by which memantine regulates amyloid metabolism is not clear. It has been shown that increased neuronal activity leads to increased APP production, a likely precursor to $\mathrm{A} \beta$ plaque formation (Cirrito et al, 2005). Thus, blockade of NMDA receptors by memantine could reduce neuronal activity and subsequently lower APP production. In support of this hypothesis, we noticed that the lower dose of memantine $(5 \mathrm{mg} /$ $\mathrm{kg}$ ) exerted stronger effects in reducing $\mathrm{A} \beta$ plaque number and burden than the two higher doses $(10 \mathrm{mg}$, and $20 \mathrm{mg} /$ $\mathrm{kg}$ ) (Figure 3). Thus, it is possible that lower memantine doses may block just enough neuronal activity to lower amyloid production, while higher doses block so much neuronal activity that APP degradation and clearance mechanisms are also decreased. Our experimental design was such that the animals began treatment before the appearance of plaques would be expected to occur in the brain. Thus, our results cannot address the question whether memantine has the capacity to prevent the formation of new plaques or to reduce the number of $\mathrm{A} \beta$ plaques already formed.

In our study, we found that memantine administration increased synaptic density in the molecular layer of the dentate gyrus in both $\mathrm{Tg}+$ and $\mathrm{Tg}-$ mice; in fact, memantine-treated $\mathrm{Tg}+$ mice tended to have a greater quantity of synapses than vehicle-treated $\mathrm{Tg}-$ mice. The molecular layer of the dentate gyrus is one of the first regions to show amyloid deposition and synapse loss in the Tg2576 mouse model of AD (Su and Ni, 1998; Reilly et al, 2003; Dong et al, 2007). However, it is difficult to know the implications of increases in synapse density after memantine administration in Tg2576 mice. While this could represent a neuroprotective effect, it could also be 

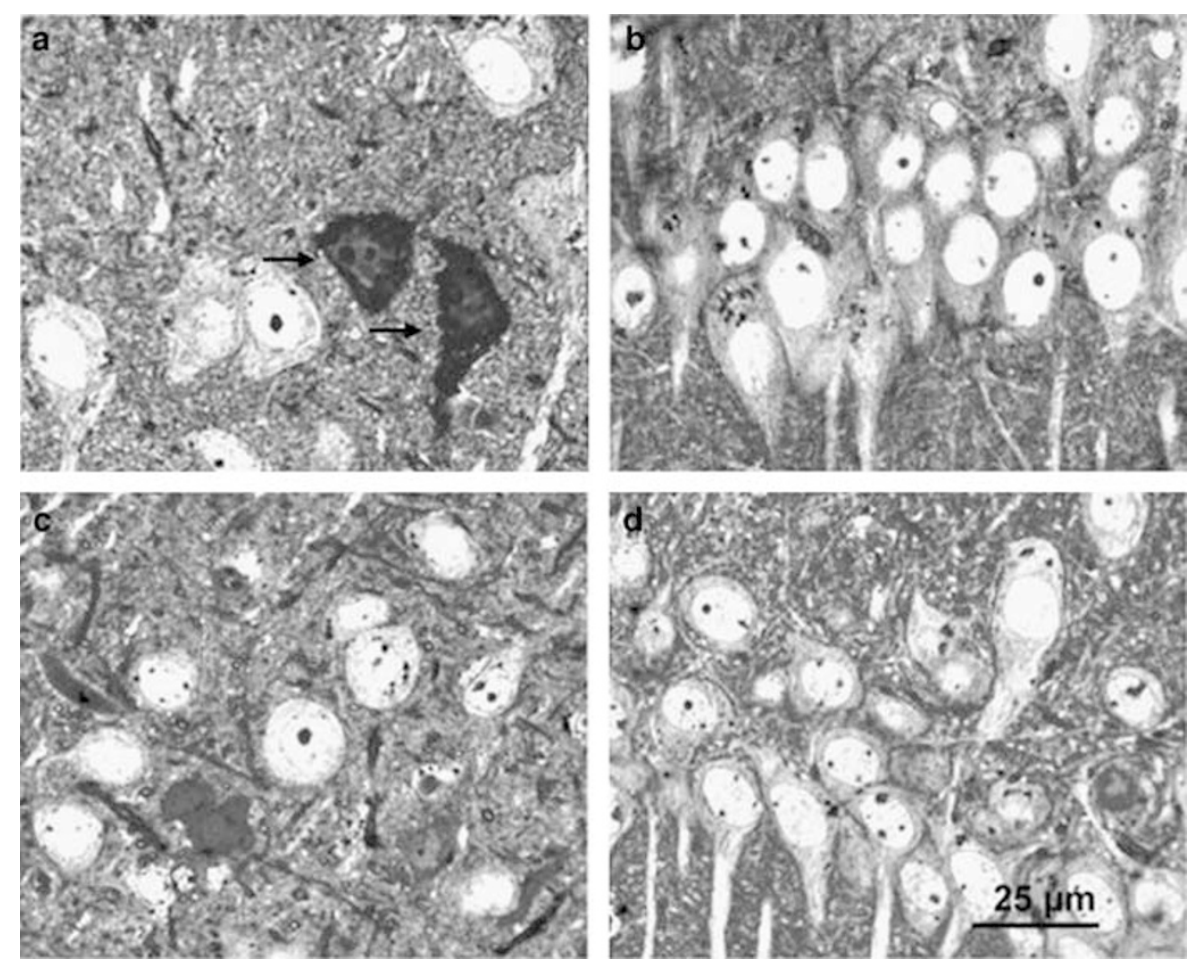

Figure 4 Neurons in the retrosplenial cortex and CAI subregion of the hippocampus of $\mathrm{Tg}+$ mice following chronic administration with $20 \mathrm{mg} / \mathrm{kg}$ (panel a and b) and $5 \mathrm{mg} / \mathrm{kg}$ (panel c and d). The neurons have a normal morphological appearance without cytoplasmic vacuoles in both the retrosplenial cortex (panel $\mathrm{a}$ and $\mathrm{c}$ ) and CAI of the hippocampus (panel b and d). However, a few dark stained cells in the retrosplenial cortex showed the feature of degeneration (panel a, arrows indicated). Bar in panel $d$ also applies to $a, b$ and $c$.

compensatory to memantine-induced axonal degeneration. Since too many as well as too few synapses could adversely impact neuronal function, caution should be used in interpreting the observed changes in synapse density after memantine treatment.

We observed no neuronal vacuolization or other histopathological changes in the hippocampus, posterior cingulate and retrosplenial cortices at the light microscopy level after memantine administration as previously reported after the administration of NMDA antagonists (Fix et al, 1993, 1994; Creeley et al, 2008). However, our observation that chronic memantine administration was associated with axonal degeneration in the hippocampus may relate to other reported neurotoxic effects of NMDA antagonists (eg PCP, MK-801) (Low and Roland, 2004). The use of NMDA antagonists as therapeutic agents for neuropsychiatric disorders thought to include a component of neurodegeneration has been investigated for many years. However, their use for this purpose has been hampered by observations of adverse behavioral effects such as hallucinations and memory disturbances in humans, and reports of neuronal vacuolization, neuronal and axonal degeneration, and induction of heat-shock protein in rodents (Olney et al, 1989, 1991; Sharp et al, 1992). Memantine, at doses somewhat higher than the doses used in this study $(50 \mathrm{mg} / \mathrm{kg})$, has been shown to produce neurodegenerative effects in the rat (Creeley et al, 2006). While the axonal degeneration induced by high doses of memantine may occur because of direct effects on neurons, indirect effects on oligodendrocytes may also be possible. Notably, NMDA receptors are ubiquitous within the CNS and are expressed not only on neurons, but also on glial cells (for review see Verkhratsky and Kirchhoff, 2007). Oligodendrocytes are important for the survival as well as function of neurons (Lappe-Siefke et al, 2003; Popko, 2003), and thus, blockade of NMDA receptors on oligodendrocytes could eventually result in axonal degeneration. Our data lend preliminary support for this hypothesis in that we observed occasional degenerated oligodendrocyte somas in memantine-treated animals (Figure $5 e$ and $\mathrm{f}$ ).

We were surprised to find no effect of memantine on contextual memory in a fear conditioning paradigm given that we used doses similar to those previously been reported to have beneficial behavioral effects in other transgenic mouse models of AD (Minkeviciene et al, 2004; Van Dam et al, 2005; Van Dam and De Deyn, 2006). The behavior deficits we observed in $\mathrm{Tg}+$ mice replicated earlier findings using Tg2576 mice (Hsiao et al, 1996; Corcoran et al, 2002; Arendash et al, 2004; Barnes and Good, 2005; Dong et al, 2005) and thus imply validity of the behavioral test employed here. At present, the effects of memantine on behavior in transgenic mouse models of $\mathrm{AD}$ (Minkeviciene et al, 2004; Van Dam et al, 2005; Van Dam and De Deyn, 2006), as well as other models (Barnes et al, 1996; MiguelHidalgo et al, 2002; Lang et al, 2004; Woodruff-Pak et al, 2007; for review see Yuede et al, 2007) are inconsistent. Minkeviciene et al (2004) reported improved acquisition in water maze using APP/PS1 transgenic mice treated with $30 \mathrm{mg} / \mathrm{kg}$ memantine in drinking water for 3 weeks, whereas no effect was observed on retention. Conversely, Van Dam et al (2005) reported beneficial effects of a much lower dose $(2.0 \mathrm{mg} / \mathrm{kg})$ of memantine while higher doses $(10 \mathrm{mg} / \mathrm{kg})$ 

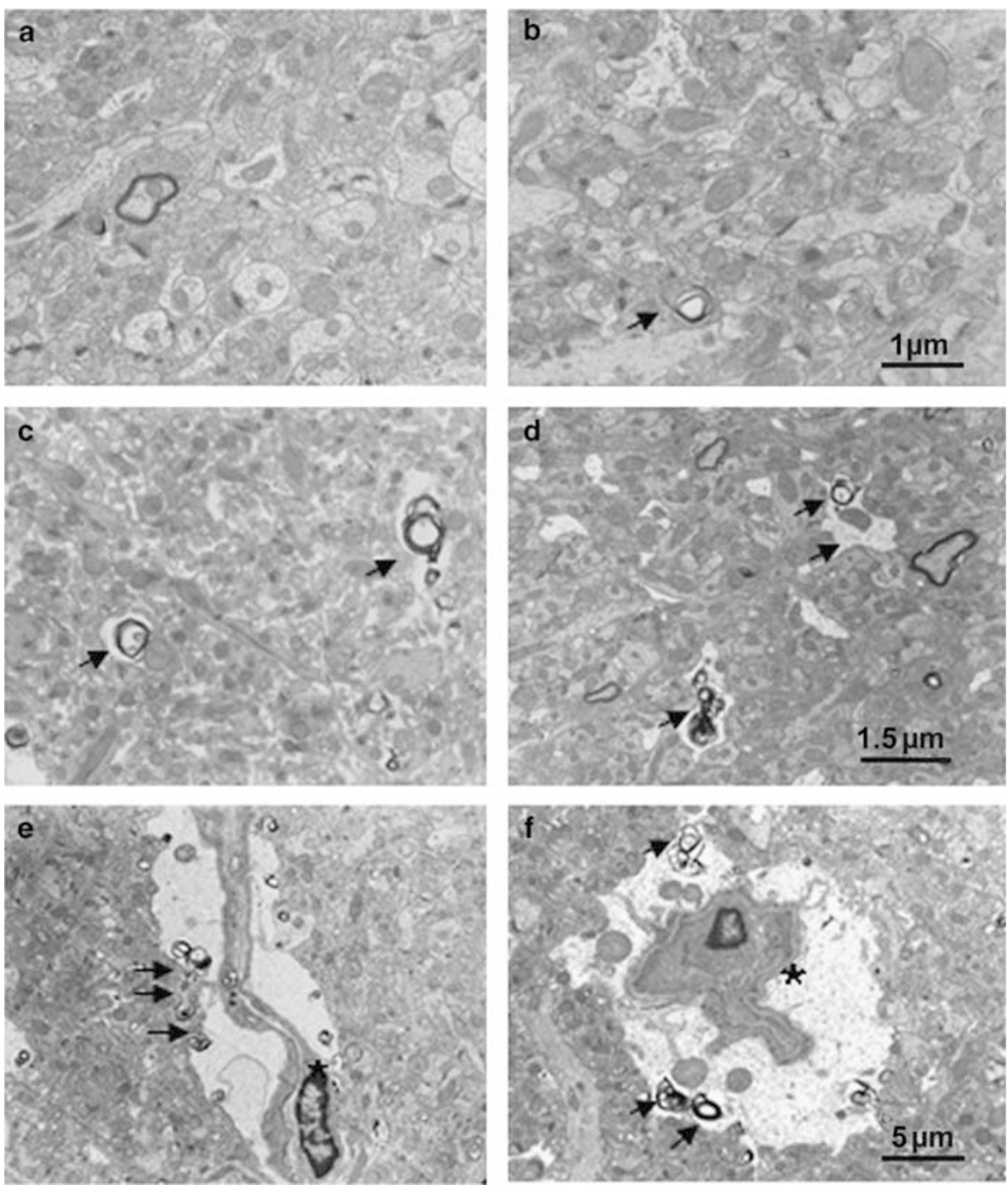

Figure 5 Electron microscope photographs taken in the molecular layer of the dentate gyrus following 6 months of memantine administration. (panel a) $\mathrm{Tg}+$ mice treated with vehicle showed decreased synapse density, but no degenerating axonal terminals. (panel b) $\mathrm{Tg}+$ mice with $5 \mathrm{mg} / \mathrm{kg}$ memantine demonstrated an increased synaptic density as compared to $\mathrm{Tg}+$ mice treated with vehicle (a), but no remarkable degenerating axons were observed. (Panel c and d) Tg + mice treated with $10 \mathrm{mg} / \mathrm{kg}$ (c) and $20 \mathrm{mg} / \mathrm{kg}$ (d) of memantine show increased degenerating axonal terminals (arrows indicated). Degenerating glial cells showing cell shrinkage with irregular space between perikarya and around neuropil (panel e and f, asterisks indicated). Bar in $b$ applies to a; Bar in d applies to c; Bar in f applies to e.
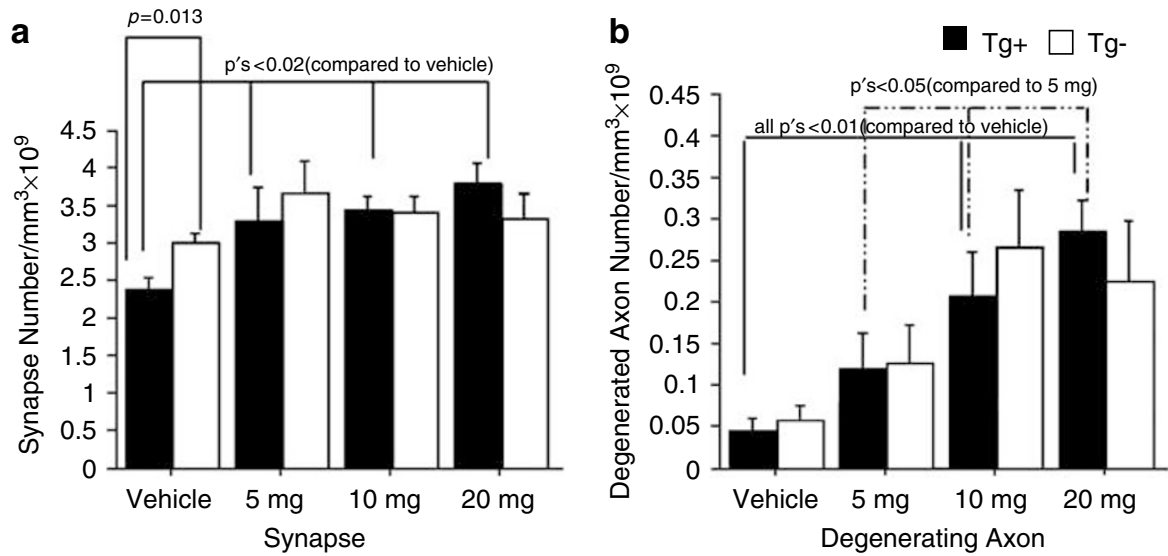

Figure 6 Synapse and degenerating axonal density in the molecular layer of dentate gyrus following 6 months of memantine administration. (Panel a) Synaptic density was significantly decreased in vehicle-treated $\mathrm{Tg}+$ mice as compared to vehicle-treated $\mathrm{Tg}-$ mice $(p=0.013)$. All three doses $(5,10$ and $20 \mathrm{mg} / \mathrm{kg}$ ) of memantine significantly increased synaptic density as compared to vehicle (p's <0.02). (Panel b) 10 and $20 \mathrm{mg} / \mathrm{kg}$ of memantine significantly increased the density of degenerating axon terminals as compared to $5 \mathrm{mg} / \mathrm{kg}$ and vehicle-treated groups. 


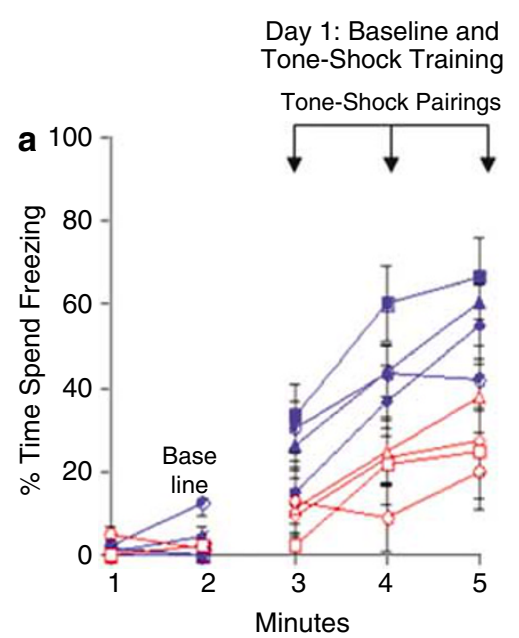
Day 2: Contextual
Fear Test
Day 3: Auditory Cue Test

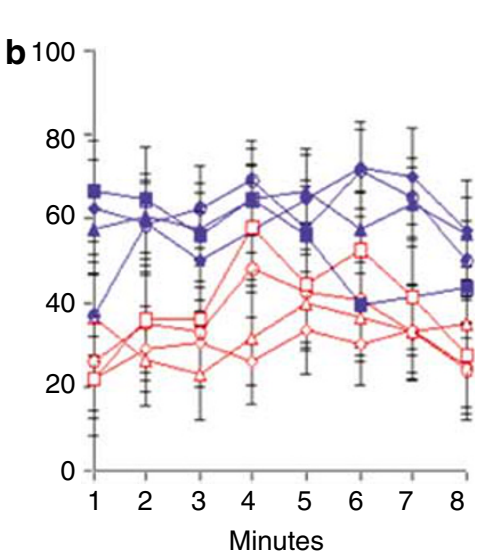

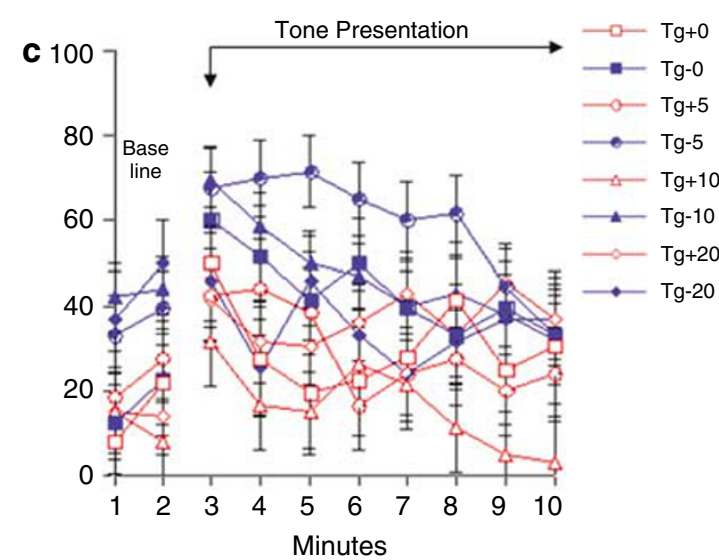

Figure 7 Freezing behavior following 6 months of memantine administration. $\mathrm{Tg}+$ mice froze significantly less than $\mathrm{Tg}-$ mice during the tone-shock pairings of the training phase (panel a). During the contextual fear test, $\mathrm{Tg}+$ animals spent significantly less time freezing than $\mathrm{Tg}-$ animals suggesting impaired contextual conditioning (panel b). $\mathrm{Tg}+$ mice froze significantly less than $\mathrm{Tg}$ - mice during the altered context baseline. During the auditory cue test, $\mathrm{Tg}+$ mice again froze significantly less than Tg- mice (panel c).

demonstrated detrimental effects in the water maze. As compared with these studies, we found that a $5 \mathrm{mg} / \mathrm{kg}$ dose was associated with better performance than a $10 \mathrm{mg} / \mathrm{kg}$ dose, even though we did not detect a significant overall effect of memantine in Tg2576 mice. Explanations for these inconsistencies include the selection of the particular mouse model, the drug doses, or the duration and route of drug dosing.

The inconsistency between our morphological and behavioral results highlights the difficulty of defining the structural basis of behavioral deficits in AD mouse models. Previous studies showed little or no correlation between the quantity of $\mathrm{A} \beta$ deposition and behavioral deficits (Terry et al, 1991; Arriagada et al, 1992; Berg et al, 1993; Westerman et al, 2002; Van Dam et al, 2003) in both humans with $\mathrm{AD}$ and animal models of $\mathrm{AD}$. Increasing evidence has indicated that soluble amyloid oligomers may be directly toxic to neuronal structure and function (Gong et al, 2003; Watson et al, 2005; Lacor et al, 2007; Shankar et al, 2007). Another explanation of the inconsistency between structure and behavior observed in this study is that the animals may have developed adaptive or compensatory responses to memantine over the extended administration period. In such a scenario, the benefits of memantine on plaque burden and synapse density might have been insufficient to produce persistent behavioral changes. Finally, it is also possible that the conditioned fear paradigm used in this study was not sensitive enough, or our sample sizes were too low to detect small behavioral changes with memantine administration.

If memantine has the potential to produce both beneficial and detrimental effects in the mammalian brain, the task is to find a dose of memantine with the former but not the latter properties. We selected three doses $(5,10$, and $20 \mathrm{mg} /$ $\mathrm{kg}$ ) for this study in an attempt to approach the therapeutic doses typically used in humans (Danysz and Parsons, 2003, Wenk et al, 2006). Previous studies in mice have reported that a $30 \mathrm{mg} / \mathrm{kg}$ oral dose of memantine in drinking water produces a steady-state plasma drug level of around $1 \mu \mathrm{M}$, which is thought to be therapeutic based on clinical studies
(Kornhuber and Quack, 1995; Minkeviciene et al, 2004). However, it is difficult to select drug doses in animal studies that are equivalent to clinical doses because the composition and responses observed in the brains of rodents and humans differ (Wenk et al, 2006). Thus, our results should not be used to predict a dose of memantine in human subjects that is both safe and effective. Rather, our results suggest that in vivo neuroimaging should be combined with clinical and cognitive assessments in an effort to determine the effects of such drugs on brain structure and function as well as symptomatology. More effective treatments are greatly needed for neurodegenerative disorders, such as $\mathrm{AD}$, and the NMDA receptor remains a viable pharmacological target in these efforts. However, drugs that act on the NMDA receptor have the potential to damage neurons as well as to protect them, and investigations of such drugs should be performed with appropriate attention to this possibility.

\section{ACKNOWLEDGEMENTS}

This work was supported by MH060883 (JGC), AG 025824 (JGC), and 5P50AG0561 (HD).

\section{DISCLOSURE}

Dr Csernansky has received research grants from the NIMH, NIA, and royalties from Medtronic for a patent held jointly with Washington University School of Medicine, has been a paid consultant for Eli Lilly and SanofiAventis, and has received speakers' honoraria from Janssen Pharmaceutica, Eli Lilly and Bristol-Myers Squibb. The other authors report no conflicts of interest.

\section{REFERENCES}

Aracava Y, Pereira EF, Maelicke A (2005). Memantine blocks alpha7 nicotinic acetylcholine receptors more potently than $N$-methyl-D-aspartate receptors in rat hippocampal neurons. J Pharmacol Exp Ther 312: 1195-1205. 
Arendash GW, Lewis J, Leighty RE, McGowan E, Cracchiolo JR, Hutton $\mathrm{M}$ et al (2004). Multi-metric behavioral comparison of APPsw and P301L models for Alzheimer's disease: linkage of poorer cognitive performance to tau pathology in forebrain. Brain Res 1012: 29-41.

Arriagada PV, Growdon JH, Hedley-Whyte ET, Hyman BT (1992). Neurofibrillary tangles but not senile plaques parallel duration and severity of Alzheimer's disease. Neurology 42: 631-639.

Bannerman DM, Yee BK, Lemaire M, Wilbrecht L, Jarrard L, Iversen SD et al (2001). The role of the entorhinal cortex in two forms of spatial learning and memory. Exp Brain Res 141: 281-303.

Bardgett ME, Boeckman $\mathrm{R}$, Krochmal $\mathrm{D}$, Fernando $\mathrm{H}$, Ahrens R, Csernansky JG (2003). NMDA receptor blockade and hippocampal neuronal loss impair fear conditioning and position habit reversal in $\mathrm{C} 57 \mathrm{Bl} / 6$ mice. Brain Res Bull 15: 131-142.

Barnes CA, Danysz W, Parsons CG (1996). Effects of the uncompetitive NMDA receptor antagonist memantine on hippocampal long-term potentiation, short-term exploratory modulation, and spatial memory in awake, freely moving rats. Er J Neurosci 8: 565-571.

Barnes P, Good M (2005). Impaired Pavlovian cued fear conditioning in Tg2576 mice expressing a human mutant amyloid precursor protein gene. Behav Brain Res 157: 107-117.

Berg L, McKeel Jr DW, Miller JP, Baty J, Morris JC (1993). Neuropathological indexes of Alzheimer's disease in demented and nondemented persons aged 80 years and older. Arch Neurol 50: $349-358$.

Buisson B, Bertrand D (1998). Open-channel blockers at the human $\alpha_{4} \beta_{2}$ neuronal nicotinic acetylcholine receptor. $\mathrm{Mol}$ Pharmacol 53: 555-563.

Chen HS, Pellegrini JW, Aggarwal SK, Lei SZ, Warach S, Jensen FE et al (1992). Open-channel block of $N$-methyl-D-aspartate (NMDA) responses by memantine: therapeutic advantage against NMDA receptor-mediated neurotoxicity. J Neurosci 11: 4427-4436.

Cirrito JR, Yamada KA, Finn MB, Sloviter RS, Bales KR, May PC et al (2005). Synaptic activity regulates interstitial fluid amyloidbeta levels in vivo. Neuron 48: 913-922.

Corcoran KA, Lu Y, Turner RS, Maren S (2002). Overexpression of hAPPswe impairs rewarded alternation and contextual fear conditioning in a transgenic mouse model of Alzheimer's disease. Learn Mem 9: 243-252.

Creeley C, Wozniak DF, Labruyere J, Taylor GT, Olney JW (2006). Low doses of memantine disrupt memory in adult rats. J Neurosci 26: 3923-3932.

Creeley C, Wozniak DF, Nardi A, Farber NB, Olney JW (2008). Donepezil markedly potentiates memantine neurotoxicity in the adult rat brain. Neurobiol Aging 29: 153-167.

Danysz W, Parsons CG (2003). The NMDA receptor antagonist memantine as a symptomatological and neuroprotective treatment for Alzheimer's disease: preclinical evidence. Int J Geriatr Psychiatry 18: S23-S32.

Ditzler K (1991). Efficacy and tolerability of memantine in patients with dementia syndrome. A double-blind, placebo controlled trial. Arzneimittelforschung 41: 773-780.

Dong H, Csernansky CA, Martin MV, Bertchume A, Vallera D, Csernansky JG (2005). Acetylcholinesterase inhibitors ameliorate behavioral deficits in the Tg2576 mouse model of Alzheimer's disease. Psychopharmacology (Berl) 181: 145-152.

Dong $\mathrm{H}$, Goico B, Martin M, Csernansky CA, Bertchume A, Csernansky JG (2004). Effects of isolation stress on hippocampal neurogenesis, memory, and amyloid plaque deposition in APP (Tg2576) mutant mice. Neuroscience 127: 601-609.

Dong H, Martin MV, Chambers S, Csernansky JG (2007). Spatial relationship between synapse loss and beta-amyloid deposition in Tg2576 mice. J Comp Neurol 500: 11-321.
Erdö SL, Schäfer M (1991). Memantine is highly potent in protecting cortical cultures against excitotoxic cell death evoked by glutamate and $N$-methyl-D-aspartate. Eur J Pharmacol 198: 215-217.

Fix AS, Horn JW, Truex LL, Smith R, Gomez E (1994). Neuronal vacuole formation in the rat posterior cingulate/retrosplenial cortex after treatment with the $N$-methyl- $d$-aspartate (NMDA) antagonist MK-801 (dizocilpine maleate). Acta Neuropathol 88: 519-551.

Fix AS, Horn JW, Wightman KA, Johnson CA, Long GG, Storts RW et al (1993). Neuronal vacuolization and necrosis induced by the noncompetitive $N$-methyl-d-aspartate (NMDA) antagonist $\mathrm{MK}(+) 801$ (dizocilpine maleate): a light and electronmicroscopic evaluation of the rat retrosplenial cortex. Exp Neurol 123: 204-215.

Frankiewicz T, Pilc A, Parsons CG (2000). Differential effects of NMDA-receptor antagonists on long-term potentiation and hypoxic/hypoglycaemic excitotoxicity in hippocampal slices. Neuropharmacology 39: 631-642.

Geinisman Y, Disterhoft JF, Gundersen HJ, McEchron MD, Persina IS, Power JM et al (2000). Remodeling of hippocampal synapses after hippocampus-dependent associative learning. J Comp Neurol 417: 49-59.

Gong Y, Chang L, Viola KL, Lacor PN, Lambert MP, Finch CE et al (2003). Alzheimer's disease-affected brain: presence of oligomeric A beta ligands (ADDLs) suggests a molecular basis for reversible memory loss. Proc Natl Acad Sci USA 100: 10417-10422.

Guntern R, Bouras C, Hof PR, Vallet PG (1992). An improved thioflavine $S$ method for staining neurofibrillary tangles and senile plaques in Alzheimer's disease. Experientia 48: 8-10.

Hsiao K, Chapman P, Nilsen S, Eckman C, Harigaya Y, Younkin S et al (1996). Correlative memory deficits, A elevation and amyloid plaques in transgenic mice. Science 274: 99-102.

Kennedy MB (2000). Signal-processing machines at the postsynaptic density. Science 290: 750-754.

Knowles WD (1992). Normal anatomy and neurophysiology of the hippocampal formation. J Clin Neurophysiol 9: 252-263.

Kornhuber J, Bormann J, Retz W, Hübers M, Riederer P (1989). Memantine displaces $(3 \mathrm{H}) \mathrm{MK}-801$ at therapeutic concentrations in postmortem human frontal cortex. Eur J Pharmacol 166: 589-590.

Kornhuber J, Quack G (1995). Cerebrospinal fluid and serum concentrations of the $N$-methyl-D-aspartate (NMDA) receptor antagonist memantine in man. Neurosci Lett 195: 137-139.

Lacor PN, Buniel MC, Furlow PW, Clemente AS, Velasco PT, Mood $\mathrm{M}$ et al (2007). Abeta oligomer-induced aberrations in synapse composition, shape, and density provide a molecular basis for loss of connectivity in Alzheimer's disease. J Neurosci 27: 796-807.

Lang UE, Muhlbacher M, Hesselink MB, Zajaczkowski W, Danysz W, Danker-Hopfe H et al (2004). No nerve growth factor response to treatment with memantine in adult rats. $J$ Neural Trans 111: 181-190.

Lappe-Siefke C, Goebbels S, Gravel M, Nicksch E, Lee J, Braun PE et al (2003). Disruption of Cnp1 uncouples oligodendroglial functions in axonal support and myelination. Nat Genet 33: 366-374.

Li Q, Clark S, Lewis DV, Wilson WA (2002). NMDA receptor antagonists disinhibit rat posterior cingulate and retrosplenial cortices: a potential mechanism of neurotoxicity. J Neurosci 22: 3070-3080.

Lipton SA (2006). Paradigm shift in neuroprotection by NMDA receptor blockade: memantine and beyond. Nat Reviews 5: $160-170$.

Lipton SA (2007). Pathologically-activated therapeutics for neuroprotection: mechanism of NMDA receptor block by memantine and S-nitrosylation. Curr Drug Targets 8: 621-632. 
Low SJ, Roland CL (2004). Review of NMDA antagonist-induced neurotoxicity and implications for clinical development. Int $J$ Clin Pharmacol Ther 42: 1-14.

Lund JS, Griffiths S, Rumberger A, Levitt JB (2001). Inhibitory synapse cover on the somata of excitatory neurons in macaque monkey visual cortex. Cereb Cortex 11: 783-795.

Miguel-Hidalgo JJ, Alvarez XA, Cacabelos R, Quack G (2002). Neuroprotection by memantine against neurodegeneration induced by beta-amyloid (1-40). Brain Res 958: 210-221.

Minkeviciene R, Banerjee P, Tanila H (2004). Memantine improves spatial learning in a transgenic mouse model of Alzheimer's disease. J Pharmacol Exp Ther 311: 677-682.

Olney JW, Labruyere J, Price MT (1989). Pathological changes induced in cerebrocortical neurons by phencyclidine and related drugs. Science 244: 1360-1362.

Olney JW, Labruyere J, Wang G, Wozniak DF, Price MT, Sesma MA (1991). NMDA antagonist neurotoxicity: mechanism and prevention. Science 254: 1515-1518.

Popko B (2003). Myelin: not just a conduit for conduction. Nat Genet 33: 327-328.

Probst A, Basler V, Bron B, Ulrich J (1983). Neuritic plaques in senile dementia of Alzheimer type: a Golgi analysis in the hippocampal region. Brain Res 268: 249-254.

Reilly JF, Games D, Rydel RE, Freedman S, Schenk D, Young WG et al (2003). Amyloid deposition in the hippocampus and entorhinal cortex: quantitative analysis of a transgenic mouse model. Proc Natl Acad Sci USA 100: 4837-4842.

Reisberg B, Doody R, Stoffler A, Schmitt F, Ferris S, Mobius HJ (2003). Memantine in moderate-to-severe Alzheimer's disease. $N$ Engl J Med 348: 1333-1341.

Shankar GM, Bloodgood BL, Townsend M, Walsh DM, Selkoe DJ, Sabatini BL (2007). Natural oligomers of the Alzheimer amyloidbeta protein induce reversible synapse loss by modulating an NMDA-type glutamate receptor-dependent signaling pathway. J Neurosci 27: 2866-2875.

Sharp FR, Butman M, Wang S, Koistinaho J, Graham SH, Sagar SM et al (1992). Haloperidol prevents induction of the hsp70 heat shock gene in neurons injured by phencyclidine (PCP), MK801, and ketamine. J Neurosci Res 33: 605-616.

Stern EA, Bacskai BJ, Hickey GA, Attenello FJ, Lombardo JA, Hyman BT (2004). Cortical synaptic integration in vivo is disrupted by amyloid-beta plaques. J Neurosci 24: 4535-4540.

Su Y, Ni B (1998). Selective deposition of amyloid-protein in the entorhinal-dentate projection of a transgenic mouse model of Alzheimer's disease. J Neurosci Res 53: 177-186.

Terry RD, Masliah E, Salmon DP, Butters N, DeTeresa R, Hill R et al (1991). Physical basis of cognitive alterations in Alzheimer's disease: synapse loss is the major correlate of cognitive impairment. Ann Neurol 30: 572-580.

Unger C, Svedberg MM, Yu WF, Hedberg MM, Nordberg A (2006). Effect of subchronic treatment of memantine, galantamine, and nicotine in the brain of $\mathrm{Tg} 2576$ (APPswe) transgenic mice. J Pharmacol Exp Ther 317: 30-36.
Van Dam D, Abramowski D, Staufenbiel M, De Deyn PP (2005). Symptomatic effect of donepezil, rivastigmine, galantamine and memantine on cognitive deficits in the APP23 model. Psychopharmacology 180: 177-190.

Van Dam D, De Deyn PP (2006). Cognitive evaluation of diseasemodifying efficacy of galantamine and memantine in the APP23 model. Eur Neuropsychopharmacol 16: 59-69.

Van Dam D, D’Hooge R, Staufenbiel M, Van Ginneken C, Van Meir F, De Deyn PP (2003). Age-dependent cognitive decline in the APP23 model precedes amyloid deposition. Eur J Neurosci 17: 388-396.

Verkhratsky A, Kirchhoff F (2007). NMDA receptors in glia. Neuroscience 13: 28-37.

Watson AH (1988). Antibodies against GABA and glutamate label neurons with morphologically distinct synaptic vesicles in the locust central nervous system. Neuroscience 26: 3-44.

Watson D, Castaño E, Kokjohn TA, Kuo YM, Lyubchenko Y, Pinsky D et al (2005). Physicochemical characteristics of soluble oligomeric Abeta and their pathologic role in Alzheimer's disease. Neurol Res 27: 869-881.

Weller M, Finiels-Marlier F, Paul SM (1993). NMDA receptormediated glutamate toxicity of cultured cerebellar, cortical and mesencephalic neurons: neuroprotective properties of amantadine and memantine. Brain Res 613: 143-148.

Wenk GL, Danysz W, Mobley SL (1995). MK-801, memantine and amantadine show neuroprotective activity in the nucleus basalis magnocellularis. Eur J Phramacol 293: 267-270.

Wenk GL, Parsons CG, Danysz W (2006). Potential role of $N$ methyl-D-aspartate receptors as executors of neurodegeneration resulting from diverse insults: focus on memantine. Behav Pharmacol 17: 411-424.

Wenk GL, Zajaczkowski W, Danysz W (1997). Neuroprotection of acetylcholinergic basal forebrain neurons by memantine and neurokinin B. Behav Brain Res 83: 129-133.

West MJ, Gundersen HJ (1990). Unbiased stereological estimation of the number of neurons in the human hippocampus. J Comp Neurol 296: 1-22.

West MJ, Kawas CH, Stewart WF, Rudow GL, Troncoso JC (2004). Hippocampal neurons in pre-clinical Alzheimer's disease. Neurobiol Aging 25: 1205-1212.

Westerman MA, Cooper-Blacketer D, Mariash A, Kotilinek L, Kawarabayashi T, Younkin LH et al (2002). The relationship between Abeta and memory in the $\mathrm{Tg} 2576$ mouse model of Alzheimer's disease. $J$ Neurosci 22: $1858-1867$.

Woodruff-Pak DS, Tobia MJ, Jiao X, Beck KD, Servatius RJ (2007). Preclinical investigation of the functional effects of memantine and memantine combined with galantamine or donepezil. Nueropsychopharmacology 32: 1284-1294.

Yuede CM, Dong H, Csernansky JG (2007). Anti-dementia drugs and hippocampal-dependent memory in rodents. Behav Pharmacol 18: 347-363. 